\title{
Mechanical properties analysis of emulsified asphalt cold regeneration under layer based on the orthogonal design
}

\author{
Yanhai Yang ${ }^{1, ~ a, ~ S h u a i ~ D o n g ~}{ }^{1, b}$, Ye Yang ${ }^{1, c}$ \\ ${ }^{1}$ Shenyang, Liaoning, China

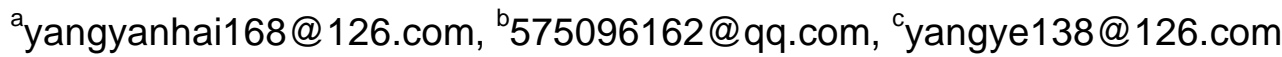

Keywords: Road Engineering; Asphalt Pavement; Emulsified Asphalt Cold Recycling; ABAQUS Simulation; Orthogonal Test; Mechanical Response

Abstract. To study the mechanical properties of emulsified asphalt cold recycled materials, and recommend reasonable structural parameters. Using orthogonal experiment design method the ABAQUS finite element analysis software to simulate, range method is used to analyze the simulation results. When the emulsified asphalt cold recycled materials thickness is more than $10 \mathrm{~cm}$, modulus is greater than $800 \mathrm{MPa}$; The cement stable macadam mixture thickness is more than $40 \mathrm{~cm}$, modulus is greater than $1600 \mathrm{MPa}$; The soil base modulus is more than $70 \mathrm{MPa}$, surfacing deflection of asphalt pavement, maximum shear stress and tension stress on the bottom of AC-10 and emulsified asphalt cold regeneration under layer are well. When the structure parameters are under the reasonable condition, emulsified asphalt cold recycled materials used as asphalt pavement under layer completely meet the requirements.

\section{Introduction}

More than $90 \%$ of provincial trunk highways in our country are the semi-rigid base asphalt pavement, the design life of asphalt pavement is about 12 15 years. By the end of 2014, The national highway mileage is more than 4.4 million kilometers. $10 \%$ of pavement are in need of major repair every year, major repairs will produce a lot of waste asphalt of pavement materials every year. Emulsified asphalt cold recycling technology is recycled asphalt pavement material according to a certain proportion of fresh material, emulsified asphalt, cement and water mix at room temperature, and paved a pavement at room temperature, then forms pavement structure layer[1-6]. Emulsified asphalt cold regeneration technology can effectively solve the problem such as the short of the existing asphalt pavement construction period, harmful gases produced in the construction process, and at the same time reducing the maintenance environmental pollution, energy consumption and waste materials to reduce the mountain mining and the asphalt resource demand, and can reduce the traffic and customer inconvenience, it is very suitable for road repair and maintenance[7-10]. Based on previous work experience, emulsified asphalt cold recycling as a layer below the mechanical properties of materials by using orthogonal test method using ABAQUS simulation software for simulation and analysis studies, theoretical foundation for the widespread application of emulsified asphalt cold recycling technology.

\section{Surface Structure model}

In view of the emulsified asphalt cold recycled materials as the layer below, research internal stress of pavement structure parameters change and its influence on road table deflection, analysis methods and material parameters are shown in table 1, using L16 (45) orthogonal table analysis[11-13], orthogonal test table are shown in table 2.

Tab.1 Pavement structure and material parameters

\begin{tabular}{|c|c|c|c|}
\hline Material names & Thickness/cm & $\begin{array}{c}\text { The compressive modulus } \\
\text { of resilience/MPa }\end{array}$ & Poisson's ratio \\
\hline AC-10 & 3 & 1200 & 0.25 \\
\hline $\begin{array}{c}\text { Emulsified asphalt cold recycled } \\
\text { materials }\end{array}$ & $8 / 10 / 12 / 14$ & $600 / 800 / 1000 / 1200$ & 0.25 \\
\hline Cement stabilized crushed stone & $30 / 40 / 50 / 60$ & $1500 / 1600 / 1700 / 1800$ & 0.25 \\
\hline Subgrade & & $40 / 70 / 100 / 130$ & 0.40 \\
\hline
\end{tabular}


Tab.2 Orthogonal experiment L16（45）

\begin{tabular}{|c|c|c|c|c|c|}
\hline The column & $\mathbf{A}$ & B & $\mathbf{C}$ & D & $\mathbf{E}$ \\
\hline Experiment & $\begin{array}{c}\text { Thickness of } \\
\text { emulsified asphalt } \\
\text { cold recycling } \\
\text { material/cm }\end{array}$ & $\begin{array}{c}\text { Modulus of } \\
\text { emulsified asphalt } \\
\text { cold regeneration } \\
\text { material/Mpa }\end{array}$ & $\begin{array}{c}\text { Thickness of } \\
\text { cement stabilized } \\
\text { macadam/cm }\end{array}$ & $\begin{array}{c}\text { Modulus of cement } \\
\text { stabilized macadam } \\
\text { /Mpa }\end{array}$ & $\begin{array}{c}\text { Modulus of } \\
\text { soil base } \\
\text { /Mpa }\end{array}$ \\
\hline 1 & 8 & 600 & 30 & 1500 & 40 \\
\hline 2 & 8 & 800 & 40 & 1600 & 70 \\
\hline 3 & 8 & 1000 & 50 & 1700 & 100 \\
\hline 4 & 8 & 1200 & 60 & 1800 & 130 \\
\hline 5 & 10 & 600 & 40 & 1700 & 130 \\
\hline 6 & 10 & 800 & 30 & 1800 & 100 \\
\hline 7 & 10 & 1000 & 60 & 1500 & 70 \\
\hline 8 & 10 & 1200 & 50 & 1600 & 40 \\
\hline 9 & 12 & 600 & 50 & 1800 & 70 \\
\hline 10 & 12 & 800 & 60 & 1700 & 40 \\
\hline 11 & 12 & 1000 & 30 & 1600 & 130 \\
\hline 12 & 12 & 1200 & 40 & 1500 & 100 \\
\hline 13 & 14 & 600 & 60 & 1600 & 100 \\
\hline 14 & 14 & 800 & 50 & 1500 & 130 \\
\hline 15 & 14 & 1000 & 40 & 1800 & 40 \\
\hline 16 & 14 & 1200 & 30 & 1700 & 70 \\
\hline
\end{tabular}

Finite element model description. Finite element software ABAQUS is adopted to establish the three-dimensional finite element model[14-15]. Take $6 \mathrm{~m}$ in the $\mathrm{x}$ and $\mathrm{y}$ direction, take $3 \mathrm{~m}$ in the $\mathrm{z}$ direction.Make origin slots on the wheel center point, $\mathrm{x}$ axis parallel to the direction of driving, $\mathrm{y}$ axis horizontal vertical driving directions and the $\mathrm{z}$ axis vertical surface.Bottom $\mathrm{x}, \mathrm{y}, \mathrm{z}$ three direction of displacement is 0 , both sides of the vertical $\mathrm{x}$ axis displacement in $\mathrm{x}$ direction is 0 , both sides of the vertical y axis displacement in y direction is 0 , contact conditions between the pavement structure layer upon layer is given priority to with inter layer completely continuous[16]. Use standard tandem-axle loads $100 \mathrm{kN}$, tire pressure is $0.7 \mathrm{MPa}$, wheel radius of pressure is $10.65 \mathrm{~cm}$, center distance is $31.95 \mathrm{~cm}$.

Calculation index. Asphalt pavements under traffic loading, mainly bear the horizontal and vertical loads, so choose the deflection on road table wheel gap center,and maximum shear stress and tensile stress on emulsified asphalt cold regeneration layer as parameter.

\section{Surface Structure model}

Emulsified asphalt recycling layer. We study the changing rules of maximum shear stress and tensile stress on the emulsified asphalt cold regeneration by changing the thickness and modulus of emulsified asphalt cold regeneration, thickness and modulus of the cement stable macadam mixture, and modulus of soil base, results are shown in table 3 .

Tab.3 Simulation results of emulsified asphalt cold recycled materials mechanical characteristics

\begin{tabular}{|c|c|c|c|c|c|c|c|}
\hline In the column & $\mathbf{A}$ & B & C & D & $\mathbf{E}$ & $\mathbf{X}$ & $\mathbf{Y}$ \\
\hline Experiment & $\begin{array}{l}\text { Thickness of } \\
\text { emulsified } \\
\text { asphalt cold } \\
\text { recycling } \\
\text { material/cm }\end{array}$ & $\begin{array}{l}\text { Modulus of } \\
\text { emulsified } \\
\text { asphalt cold } \\
\text { regeneration } \\
\text { material/Mpa }\end{array}$ & $\begin{array}{c}\text { Thickness of } \\
\text { cement } \\
\text { stabilized } \\
\text { macadam } \\
\text { /cm }\end{array}$ & $\begin{array}{c}\text { Modulus of } \\
\text { cement } \\
\text { stabilized } \\
\text { macadam } \\
\text { /Mpa }\end{array}$ & $\begin{array}{c}\text { Modulus } \\
\text { of soil } \\
\text { base/Mpa }\end{array}$ & $\begin{array}{c}\text { The } \\
\text { maximum } \\
\text { shear } \\
\text { stress/Mpa }\end{array}$ & $\begin{array}{c}\text { Tensile } \\
\text { stress on the } \\
\text { bottom } \\
\text { /Mpa }\end{array}$ \\
\hline 1 & 8 & 600 & 30 & 1500 & 40 & 0.0902 & 0.1575 \\
\hline 2 & 8 & 800 & 40 & 1600 & 70 & 0.0939 & 0.1445 \\
\hline 3 & 8 & 1000 & 50 & 1700 & 100 & 0.0966 & 0.1382 \\
\hline 4 & 8 & 1200 & 60 & 1800 & 130 & 0.0974 & 0.1344 \\
\hline 5 & 10 & 600 & 40 & 1700 & 130 & 0.0836 & 0.1193 \\
\hline 6 & 10 & 800 & 30 & 1800 & 100 & 0.0927 & 0.1420 \\
\hline 7 & 10 & 1000 & 60 & 1500 & 70 & 0.0905 & 0.1295 \\
\hline 8 & 10 & 1200 & 50 & 1600 & 40 & 0.0937 & 0.1509 \\
\hline 9 & 12 & 600 & 50 & 1800 & 70 & 0.0796 & 0.1134 \\
\hline
\end{tabular}




\begin{tabular}{|c|c|c|c|c|c|c|c|c|}
\hline \multicolumn{2}{|c|}{10} & 12 & 800 & 60 & 1700 & 40 & 0.0894 & 0.1169 \\
\hline \multicolumn{2}{|r|}{11} & 12 & 1000 & 30 & 1600 & 130 & 0.0911 & 0.1363 \\
\hline \multicolumn{2}{|r|}{12} & 12 & 1200 & 40 & 1500 & 100 & 0.0903 & 0.1376 \\
\hline \multicolumn{2}{|r|}{13} & 14 & 600 & 60 & 1600 & 100 & 0.0759 & 0.1024 \\
\hline \multicolumn{2}{|r|}{14} & 14 & 800 & 50 & 1500 & 130 & 0.0798 & 0.1097 \\
\hline \multicolumn{2}{|r|}{15} & 14 & 1000 & 40 & 1800 & 40 & 0.0854 & 0.1368 \\
\hline \multicolumn{2}{|r|}{16} & 14 & 1200 & 30 & 1700 & 70 & 0.0901 & 0.1461 \\
\hline \multirow{9}{*}{$\mathrm{X}$} & $\mathrm{I}$ & 0.3781 & 0.3293 & 0.3641 & 0.3508 & 0.3587 & & \\
\hline & II & 0.3605 & 0.3558 & 0.3532 & 0.3546 & 0.3541 & & \\
\hline & III & 0.3504 & 0.3636 & 0.3497 & 0.3597 & 0.3555 & & \\
\hline & IIII & 0.3312 & 0.3715 & 0.3532 & 0.3551 & 0.3519 & & \\
\hline & $\mathrm{I} / \mathrm{K}$ & 0.0945 & 0.0823 & 0.0910 & 0.0877 & 0.0897 & & \\
\hline & $\mathrm{II} / \mathrm{K}$ & 0.0901 & 0.0890 & 0.0883 & 0.0887 & 0.0885 & & \\
\hline & $\mathrm{III} / \mathrm{K}$ & 0.0876 & 0.0909 & 0.0874 & 0.0899 & 0.0889 & & \\
\hline & $\mathrm{IIII} / \mathrm{K}$ & 0.0828 & 0.0929 & 0.0883 & 0.0888 & 0.0880 & & \\
\hline & $\mathrm{R}$ & 0.0117 & 0.0106 & 0.0036 & 0.0022 & 0.0017 & & \\
\hline \multirow{9}{*}{$\mathrm{Y}$} & $\mathrm{I}$ & 0.5746 & 0.4926 & 0.5819 & 0.5343 & 0.5621 & & \\
\hline & II & 0.5417 & 0.5131 & 0.5382 & 0.5341 & 0.5335 & & \\
\hline & III & 0.5042 & 0.5408 & 0.5122 & 0.5205 & 0.5202 & & \\
\hline & IIII & 0.4950 & 0.5690 & 0.4832 & 0.5266 & 0.4997 & & \\
\hline & $\mathrm{I} / \mathrm{K}$ & 0.1437 & 0.1232 & 0.1455 & 0.1336 & 0.1405 & & \\
\hline & $\mathrm{II} / \mathrm{K}$ & 0.1354 & 0.1283 & 0.1346 & 0.1335 & 0.1334 & & \\
\hline & $\mathrm{III} / \mathrm{K}$ & 0.1261 & 0.1352 & 0.1281 & 0.1301 & 0.1301 & & \\
\hline & $\mathrm{IIII} / \mathrm{K}$ & 0.1238 & 0.1423 & 0.1208 & 0.1317 & 0.1249 & & \\
\hline & $\mathrm{R}$ & 0.0199 & 0.0191 & 0.0247 & 0.0035 & 0.0156 & & \\
\hline
\end{tabular}

Can be seen from table 3, the maximum shear stress test show that: $R_{A}>R_{B}>R_{C}>R_{D}>R_{E}$, the order of its effect is: thickness and modulus of emulsified asphalt cold recycled materials, thickness and modulus of the cement stable macadam, and the modulus of soil base. Drawing the influence to emulsified asphalt cold regeneration layer of maximum shear stress changing trends as shown in figure 1.
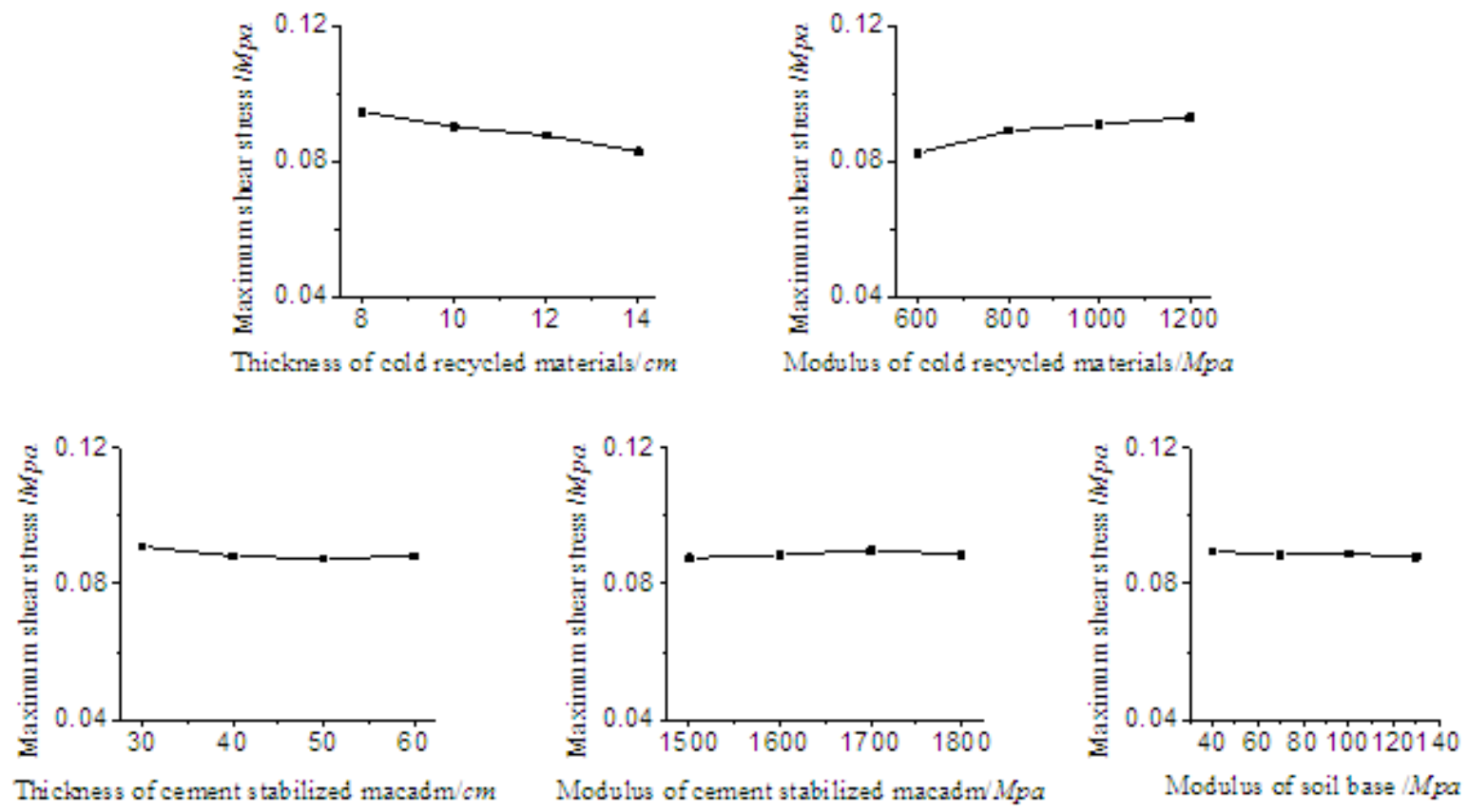

Fig.1 Test factors affect maximum shear stress

Can be seen from figure 1, the maximum shear stress in emulsified asphalt cold regeneration layer is smaller, thickness and modulus of emulsified asphalt cold recycled materials, thickness and modulus of the cement stable macadam mixture, and the modulus of soil base impress little on the maximum shear stress in the emulsified asphalt cold regeneration layer. 
Can be seen from table 3, tensile stress on the bottom of emulsified asphalt cold regeneration layer test: $R_{C}>R_{A}>R_{B}>R_{E}>R_{D}$, the order of its effect is: the thickness of cement stabilized macadam, thickness and modulus of emulsified asphalt cold recycled materials, modulus of soil base and modulus of cement stabilized macadam. Drawing the influence to emulsified asphalt cold regeneration layer of tensile stress on the bottom changing trends as shown in figure 2.
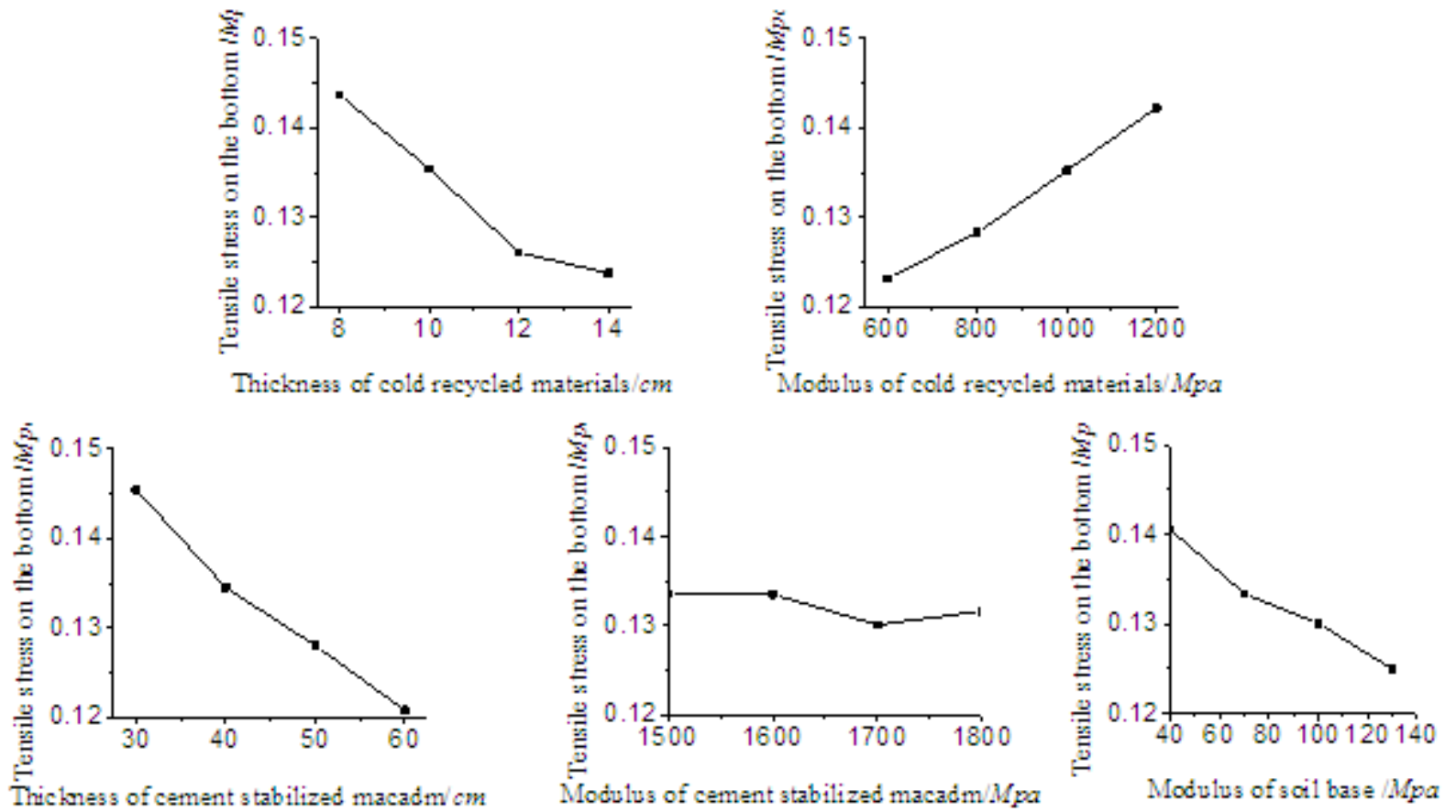

Fig. 2 Test factors affect emulsified asphalt material layer bottom bending tensile stress

Can be seen from figure 2, as the thickness of the emulsified asphalt cold recycled materials, thickness of the cement stable macadam, and the modulus of soil base increase, the tensile stress on the bottom of emulsified asphalt cold regeneration decreases. It also increases when the modulus of emulsified asphalt cold recycled materials increases. But it changes a little, its scope is within 0.03, the influence of modulus of cement stabilized macadam is smaller.

\section{Conclusions}

The maximum shear stress of emulsified asphalt cold regeneration layer is smaller, the thickness and modulus of emulsified asphalt cold recycled materials, thickness and modulus of the cement stable macadam, and modulus of soil impressed a little on the maximum shear stress in the emulsified asphalt cold regeneration layer. The tensile stress on the bottom of emulsified asphalt cold regeneration layer decreases as the thickness of the emulsified asphalt cold recycled materials, the thickness of the cement stable macadam, and the modulus of soil base increase, it also increases as the modulus of emulsified asphalt cold regeneration material increase. But small change is within $0.03 \mathrm{MPa}$, the influence of modulus of cement stabilized macadam is smaller.

The thickness of the emulsified asphalt cold recycled materials is more than $10 \mathrm{~cm}$, modulus is greater than $800 \mathrm{Mpa}$; the thickness of the cement stable macadam mixture is more than $40 \mathrm{~cm}$, modulus is greater than $1600 \mathrm{Mpa}$; when soil base modulus is greater than $70 \mathrm{Mpa}$, the effect of surfacing deflection, the tensile stress on the bottom and the maximum shear stress on the AC-10 surface and on the emulsified asphalt cold regeneration layer are good. 


\section{Acknowledgement}

The results presented here are part of a research project by Yang Ye in the Department of Traffic Engineering at Shenyang Jianzhu University, Shen Yang, Liao Ning, China.

\section{References}

[1] Xiujiun Li, Fangzhi Shi. Analysis on mechanical performance of cold recycled pavement with emulsified asphalt [J], Journal of Highway and Transportation Research and Development, 2012,29(11): 30-35.(in Chinese)

[2] Technical Specification for Asphalt Pavement Regeneration[S]. JTG F41-2008. Beijing: China Communications Press, 2008.(in Chinese)

[3] GIULIANi F. X-ray diffraction method for studying cement-modified bitumen: Emulsion Mixtures in Asphalt Pavement Cold Recycling[R]. Vermont South, Victoria, Spain: ARRB Group Limited, 2001.

[4] TIA M, WOOD L E. Use of asphalt emulsion and foamed asphalt in cold-recycled asphalt paving mixtures [J]. Transportation Research Record, 1983, 898:315-321.

[5] Anonymous. Research and Markets: Fundamentals of Performance Evaluation of Computer and Telecommunications Systems - State-of-the-Art Technical Performance Evaluation[J]. M2 Presswire, 2010.

[6] S. Pirmohammad, M.R. Ayatollahi. Fracture resistance of asphalt concrete under different loading modes and temperature conditions[J]. Construction and Building Materials, 2014, Vol.53.

[7] Zhaoguang Hou, Zhouqing Zhao, Ronghua Ying. Analysis of the mechanical response of cold recycled base pavement structure [J]. Journal of Wuhan University of Technology(Transportation Science \& Engineering) ,2011. 35(3): 591-594.(in Chinese)

[8] Yongjoo Kim, Hosin David Lee. Performance evaluation of Cold In-Place Recycling mixtures using emulsified asphalt based on dynamic modulus, flow number, flow time, and raveling loss[J].KSCE Journal of Civil Engineering, 2012, Vol.16 (4), pp.586-593.

[9] María José Martínez-Echevarría,Rodrigo Miró Recasens,María del Carmen Rubio Gámez,Antonio Menéndez Ondina. In-laboratory compaction procedure for cold recycled mixes with bituminous emulsions[J]. Construction and Building Materials, 2012, Vol.36, pp.918-924.

[10] Xu, Jian, Huang, Songchang, Qin, Yongchun, Li, Feng. The Impact of Cement Contents on the Properties of Asphalt Emulsion Stabilized Cold Recycling Mixtures[J]. International Journal of Pavement Research and Technology, 2011, Vol.4 (1), pp.48-55.

[11]Jiang He. Mechanism analysis of emulsified asphalt cold recycled mixture [J]. Applied Mechanics and Materials, 2013, Vol.405-408, pp.1761-1766.

[12] Yanhai Yang, Ye Yang, Junsheng Wen, Xiaoxi Gao. Experimental research on molding and curing for emulsified asphalt cold recycling mixture using orthogonal test[J], Journal of Liaoning Provincial College of Communications, 2014, 16(2):1-5.(in Chinese)

[13] Jicun Xu, Chuanyi Zhuang, Yali Ye, Xiaojin Song. Based on the orthogonal design of aggregate basic mechanics response of asphalt pavement grey entropy analysis[J], Journal of China \& Foreign Highway ,2013,33 (4):268-272.(in Chinese)

[14] Gongyun Liao, Xiaoming Huang. Application of ABAQUS finite elements software in road engineering[M], Nanjing: Southeast University Publishing House, 2008.(in Chinese)

[15] Yuzhuo Wang, Chuanguo Fu, Application of ABAQUS finite elements software in structural engineering [M], Beijing: China Building Industry Press, 2010.(in Chinese)

[16] Minjiang Zhang, Zhitao Song, Baoyang Yu, Reasonable structure parameters analysis of the upper base of the graded crushed stone asphalt pavement[J].Journal of Shenyang Jianzhu University(Natural Science) ,2012,28（3）:460-466.(in Chinese) 